\title{
BODY MASS INDEX - PROPOSED NORMS FOR CHILDREN AND YOUTHS
}

\author{
Romuald Stupnicki, Pawel Tomaszewski, Katarzyna Milde \\ University of Physical Education in Warsaw, Poland
}

\begin{abstract}
The aim of the study was to establish normal BMI values vs. age for children and youths having normal body fat content and to confront them with Cole's cut-off points. In cohorts of 1373 boys and 1805 girls, aged 7-20 years, body fat content was determined from 3 skinfolds (triceps, subscapular, abdominal) using Slaughter's equations. Next, 1069 boys and 759 girls with acceptable fat percentage (NF groups) were selected and for them log BMI values were computed. Equations of log BMI vs. age (means and SD) computed for NF groups served to present the proposed BMI norms. The obtained upper limits (mean $\log +2 \mathrm{SD}$ ) for boys and girls aged 19 years were 24.6 and 24.5, respectively, and the corresponding body fat contents -23.7 and 24.1 , respectively. Inasmuch BMI does not reflect the real body fat content, the presented norms, based on acceptable body fat content, seem to reflect the weight-height relations better than those derived from unselected population data.
\end{abstract}

Keywords: BMI, body fat content, children, adolescents

\section{INTRODUCTION}

The steadily increasing rate of overweight and obesity among children and youths, observed throughout the last three decades [3, 28, 40], has become a seriously epidemic social problem, especially in developed countries [25, 29]. The IOTF reports from 2005 [17] indicate that $20 \%$ of European children are overweight or obese and about 400000 new cases are recorded every year. Untreated obesity at an early age may result in many health problems in adults $[1,20,37]$. About $60 \%$ of obese adolescents are expected to remain obese in adulthood [2], thus being at risk of hypertension, Type II diabetes, 
dyslipidemia, metabolic syndrome, ischaemic heart disease, etc. $[14,18,24,30]$ and, in effect, of an impaired quality of life combined with the need to remain under continuous treatment [2].

Early detection of overweight and obesity in schoolchildren is usually based on the commonly employed Body Mass Index (BMI), due to its easy use and a relatively high correlation with body fat content $[21,33]$. However, the predictive power of BMI as a measure of body fat content or of the risk of infarction is considered insufficient $[10,19]$ due to the fact that the definition of obesity refers to an excessive body fat content, the physiological risk factor, and not to the weight/height proportion. Thus, the BMI-based overweight is insufficiently associated with increased body fat content [11].

In 2000, Cole et al. [5] presented BMI norms based on a wide international study, designed for detecting overweight and obesity in children and youths aged 2-18 years. Those norms gained a wide popularity but also raised a dispute on the use of global vs. local cut-off points [4, 31], as those points have been reported to be rather population-specific [7]. Moreover, Cole's cut-off points were derived from general populations without taking into account the individual body fat content, thus not meeting the physiological criterion. The aim of this study was thus to establish reference values of BMI derived from those children and youths aged 7-20 years whose body fat content was considered acceptable and to compare those values with Cole's norms.

\section{MATERIAL AND METHODS}

Subjects: The study was conducted in 22 randomly selected schools in eastern and central Poland. The studied cohort counted 1373 boys and 1805 girls, aged 7-20 years. The study was conducted in accordance with the Helsinki declaration and was approved by the local Committee of Ethics. The equations for the body fat content (see below) served to select subjects with acceptable fat percentage; these subcohorts of boys and girls counted 1069 (Group MNF) and 759 (Group FNF), respectively.

Methodology: The following data were recorded: exact calendar age, body height and mass measured with a stadiometer (HOLTAIN, UK; accuracy $0.1 \mathrm{~cm}$ ) and medical scales (TANITA, Japan; accuracy $0.1 \mathrm{~kg}$ ), respectively. Three skinfolds (triceps, subscapular, abdominal) were measured using a skinfold calliper (HOLTAIN, UK; accuracy $0.1 \mathrm{~mm}$ ). These served to compute the 
relative body fat content using Slaughter's equations [35]. The following procedure was used to compute z-values for the percentage of body fat content: the previously established lower and upper, gender- and age-dependent limits of a reasonable fat content [39] were log means \pm 2 SD resulting in the following equations of means $\pm S D$ vs. age $(\mathrm{A})$ :

Boys: $\log \% \mathrm{~F}=\left(0.837+0.05464 \cdot \mathrm{A}-0.0023955 \cdot \mathrm{A}^{2}+0.0000378 \cdot \mathrm{A}^{3}\right) \pm$ $\left(0.0094+0.00951 \cdot \mathrm{A}-0.0005983 \cdot \mathrm{A}^{2}+0.0000115 \cdot \mathrm{A}^{3}\right.$;

Girls: $\log \% \mathrm{~F}=\left(0.8578+0.0589 \cdot \mathrm{A}-0.002639 \cdot \mathrm{A}^{2}+0.0000399 \cdot \mathrm{A}^{3}\right) \pm$ $\left(0.0634-0.00731 \cdot \mathrm{A}+0.000773 \cdot \mathrm{A}^{2}-0.00003292 \cdot \mathrm{A}^{3}+0.00000049 \cdot \mathrm{A}^{4}\right)$.

Data analysis: The values of BMI and relative body fat content were converted to logarithms prior to analysis. The data of subjects having normal body fat content (the NF groups) were arranged by age and divided into categories of $\mathrm{n}=100$ each in an overlapping way, e.g. the first category contained data 1-100, the second - 51-150, etc. (cf. [38]). For every category, mean values of age and $\mathrm{BMI}$, and of standard deviations for BMI were computed. In addition, all data were assessed with the use of cut-off points recommended by Cole et al. $[5,6]$

\section{RESULTS}

Fractional means and standard deviations of BMI values computed for boys and girls with normal body fat content are presented in Fig. 1. The respective equations are listed in Table 1.

Table 1. Equations of log (BMI) as functions of age (A) computed for boys and girls aged 7-20 years having normal body fat content

\begin{tabular}{c} 
Boys $(n=1069)$ \\
\hline Mean log $(B M I)=1.222-0.034 \cdot A+0.00415 \cdot A^{2}-0.000112 \cdot A^{3}$ \\
\hline SD $\log (B M I)=-0.0024+0.00454 \cdot A-0.000115 \cdot A^{2}$ \\
\hline Girls $(n=759)$ \\
\hline Mean log $(B M I)=1.228-0.03083 \cdot A+0.003752 \cdot A^{2}-0.0001 \cdot A^{3}$ \\
\hline SD $\log (B M I)=-0.0946+0.03 \cdot A-0.002032 \cdot A^{2}+0.000043 \cdot A^{3}$ \\
\hline
\end{tabular}



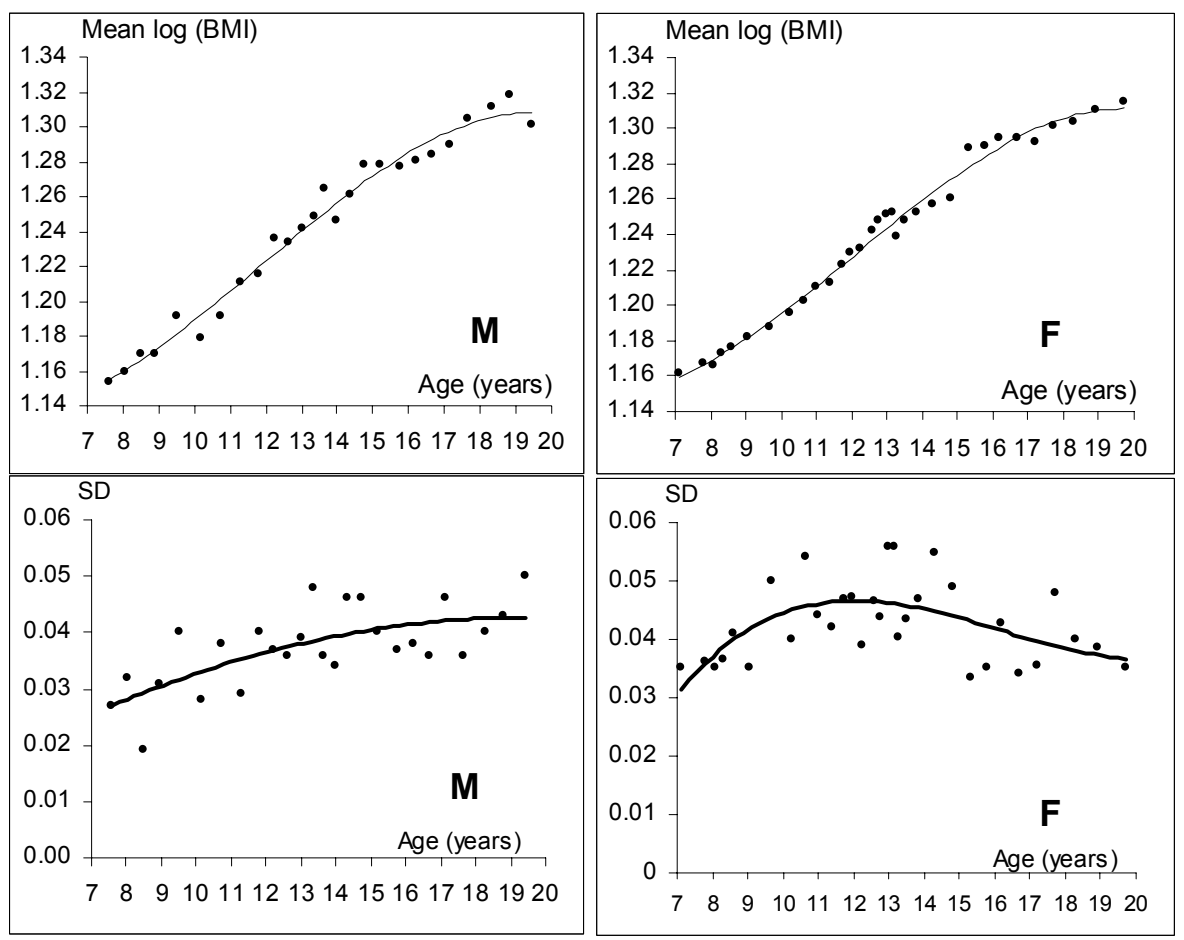

Figure 1. Fractional means and standard deviations of log BMI values in boys $(M ; n=$ $1069)$ and girls $(F ; n=759)$ with normal body fat content (Groups MNF and FNF)

The values of means and standard deviations obtained from the respective equations for adult subjects, i.e. aged 20 years, were used to compute adjusting factors for the BMI cut-off points recommended by WHO: 18.5 (underweight), 25 (overweight) and 30 (obesity). The latter two cut-off points, when applied to the age functions of body fat content, correspond, roughly, to 25 and $30 \%$ of fat in men and women. Fig. 2 presents normal BMI values vs. age, i.e. means \pm 2 SD (solid lines) and the corrected ones, i.e. means \pm standard deviations multiplied by the adjusting factors (dashed lines). 

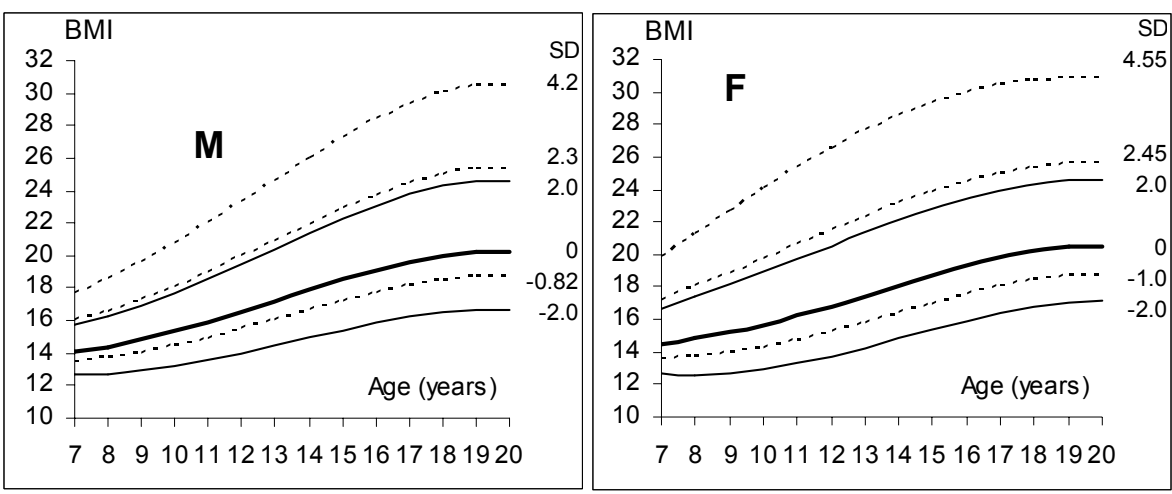

Figure 2. Proposed normal values of $B M I$ vs. age (means $\pm 2 S D$ ) in boys $(M)$ and girls $(F)$ computed from equations presented in Table 1 and adjusting factors for the 18.5, 25 and 30 cut-off points

Table 2. Standard BMI $z$-values $(-2,0,2)$ for boys and girls aged 20 years and those corresponding to the cut-off points for adults (bolded), and the respective values of body fat content $(\% \mathrm{~F})$

\begin{tabular}{ccc|ccc}
\hline & Boys & & \multicolumn{3}{c}{ Girls } \\
\hline BMI & SD & \%F & BMI & SD & \%F \\
\hline 16.6 & -2 & 14.6 & 17.1 & -2 & 16.4 \\
\hline $\mathbf{1 8 . 5}$ & -0.82 & 16.8 & $\mathbf{1 8 . 5}$ & -1.00 & 18.0 \\
\hline 20.2 & 0 & 18.6 & 20.5 & 0 & 19.9 \\
\hline 24.6 & 2 & 23.7 & 24.5 & 2 & 24.1 \\
\hline $\mathbf{2 5}$ & 2.30 & 24.6 & $\mathbf{2 5}$ & 2.45 & 25.1 \\
\hline $\mathbf{3 0}$ & 4.20 & 31.1 & $\mathbf{3 0}$ & 4.55 & 30.7 \\
\hline
\end{tabular}

Fig. 3 illustrates the discrepancies between the three modes of classification: by body fat content, by the here presented approach to BMI and by Cole's cut-off points. The most striking features are marked between gender differences in all categories and between frequencies resulting from classifying by $\% \mathrm{~F}$ or by BMI. In all cases, comparable cut-off points were applied as shown in Table 2 and in Fig. 2. Lowest percentages of normal-weight boys and girls resulted from using body fat content as the criterion. Fairly high percentages of overweight and obesity were found in girls by the $\% \mathrm{~F}$ criterion, while by BMI, especially by Cole's cut-off points, those percentages were decidedly lower - no obese girl was found by that method in contrast to nearly $13 \%$ by $\%$ F. 


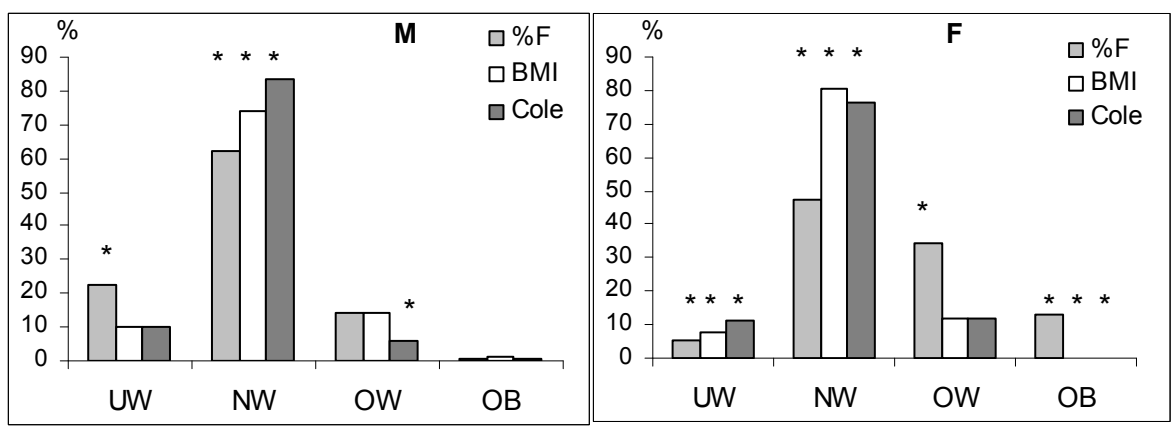

Fig. 3. Percentages of boys $(n=1373)$ and girls $(n=1805)$ aged $7-20$ years classified by body fat content, by BMI or by Cole's BMI cut-off points $[5,6]$

Legend: UW - Underweight (BMI < 18.5) or deficient \%F; NW - Normal weight or normal \%F; OW - Overweight $(25<\mathrm{BMI}<30)$ or excessive \%F; OB - Obesity; * The frequencies of boys and girls differ significantly $(p<0.05-0.001)$ in all categories except UW by Cole and OW by our BMI.

The age-related cut-off points for BMI presented in Fig. 4 show a fairly good agreement of our and Cole's data for girls. In the case of boys, our cut-off points for overweight and obesity are markedly lower from those of Cole for young boys; Cole's overweight criterion for 7-8-year-old boys corresponds to our obesity criterion.

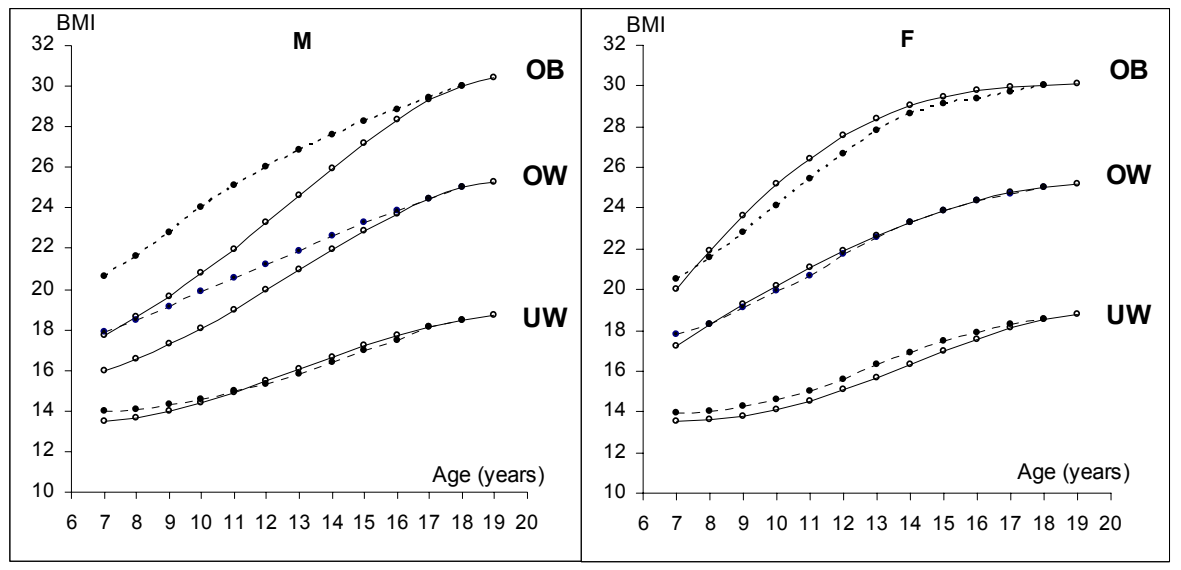

Fig. 4. Cut-off points for BMI in boys and girls as recommended by Cole et al. [5, 6] (solid lines) or as resulting from our approach based on normal body fat content (dotted lines) Legend: UW - Underweight (corresponding to adult value of 18.5); OW - Overweight (corresponding to adult value of 25); OB - Obesity (corresponding to adult value of 30 ) 


\section{DISCUSSION}

Establishing reliable reference values of somatic variables is the key factor in assessing the course of growth and development of children and youths. Of particular importance are reference values of the body fat content and of body mass indices, as these are essential for appropriately detecting overweight and obesity, the most rapidly evolving civilisation-related diseases.

Despite vast literature pertaining to BMI values in children and youths, the only approach was based on tailoring population data. The most advanced example was the paper of Cole et al. [5] who emphasised the benefits of using body fat content as the classification criterion but stated that its use was epidemiologically impossible. In this study, the normal values for BMI in the growth period were established from data recorded in subjects who had "normal" or rather "acceptable" body fat content. An attempt at establishing norms for body fat content was made earlier [39] taking into account numerous, often discordant, reports and recommendations. Inasmuch those "acceptable" ranges of body fat content were fairly wide, the upper limit (mean + 2SD) in 20-year-old subjects amounting to about $24 \%$ in both genders, the normal ranges of BMI computed for those "normal fat" subjects rendered different distributions compared with those resulting from the cut-off points derived from those recommended for adults. It should be emphasised that the generally accepted criteria of overweight and obesity in adults were derived from epidemiological studies on the risk of e.g. cardiovascular diseases and all-cause mortality [9, 12, 14]. Although studies on the risk factors associated with obesity of children and youths have been undertaken (see e.g. [15]), no conclusive data exist, so far, for children and youths, so the approach used by us, i.e. establishing the recommended values for weight/height relationships from data of subjects with normal body fat content, i.e. justified physiologically, seems to be rational.

When body fat content $(\% \mathrm{~F})$ was applied as the criterion of the appropriate body weight, the percentages of boys and girls in the "normal weight" category were significantly lower compared with applying the BMI cut-off points, either Cole's or those proposed here. On the other hand, the percentage of overweight boys was significantly lower by Cole's BMI criterion compared with either \%F or our BMI criteria. That difference was particularly striking in girls - practically none of them was found obese by either BMI criterion, while by $\% \mathrm{~F}$ almost $20 \%$ were classified as obese. The discrepancies between the $\% \mathrm{~F}$ and $\mathrm{BMI}$ criteria in detecting overweight and obesity have been reported by Ellis 
et al. [8]. They found as many as $17 \%$ of children having acceptable body fat content to be classified as overweight or obese by BMI. Other authors (e.g. [32, 36]) have also emphasised that the BMI criterion invariably leads to a reduced rate of detecting overweight and obesity compared with other methods of determining body composition. On the other hand, Laurson et al. [23] have found that $\mathrm{BMI}$ and skinfold-derived $\% \mathrm{~F}$ demonstrate reasonable agreement when used to classify adiposity status in children and adolescents. Nevertheless, using BMI alone may result in possible stigmatizing children by incorrectly classifying them as weight-deficient or obese [16].

The presented BMI reference values for girls agree fairly well with those of Cole et al. [5]. On the other hand, Cole's cut-off points for boys are markedly lower from those proposed by us to the extent that in boys aged 7-8 years Cole's cut-off points for overweight correspond to those for obesity proposed by us. In effect, our reference values enable detecting overweight in boys up to about 13 years of age and obesity up to about 15 years of age much more efficiently compared with Cole's standards. According to other authors [34], the incidence of obesity was markedly lower when Cole's cut-off points were applied compared with other reference values ( 8 and $13 \%$, respectively). The discrepancies between BMI reference values have been reported by Flegal et al. [13] who compared estimates based on various sources $[2,22,27]$. The observed inconsistencies were probably due to the different approaches used to define cut-offs and to different criteria used to select study samples [26] and, besides, due to the fact that the sampling was not based on body fat content.

The choice of methodology used to determine body fat content may be, of course, questioned as its assessment from the thickness of skinfolds cannot be regarded as accurate. Besides, the proposed "normal" or "acceptable" limits of body fat content may also be controversial as no generally acceptable values exist [10]. Yet, we consider the presented approach, however imprecise, superior to that based on unselected population data, for fat is the dominating factor that affects body mass. Moreover, when the limits of "normal" \%F were changed by $\pm 0.3 \mathrm{SD}$, the effects on BMI means and SD were virtually none.

In conclusion, the BMI cut-off points presented here seem to be better suited to reliably detect overweight and obesity in children and youths as the values were derived from data based on the physiological criterion - body fat content. Our values detect a higher percentage of young subjects, especially boys, at risk of overweight or obesity, thus enabling an earlier prevention. 


\section{REFERENCES}

1. Barker D. J., Osmond C., Forsén T. J., Kajantie E., Eriksson J.G. (2005). Trajectories of growth among children who have coronary events as adults. N Engl J Med, 353, 17, 1802-1809.

2. Branca F., Nikogosian H., Lobstein T. (2007). The challenge of obesity in the WHO European Region and the strategies for response, World Health Organization. http://www.euro.who.int/__data/assets/pdf_file/0008/98243/E89858.pdf

3. Carroll M. D., Curtin L. R., Lamb M. M., Flegal K. M. (2010). Prevalence of high body mass index in US children and adolescents, 2007-2008. JAMA, 303, 3, 242-249.

4. Chinn S., Rona R.J. (2002). International definitions of overweight and obesity for children: a lasting solution? Ann Hum Biol, 29, 3, 306-313.

5. Cole T. J., Bellizzi M. C., Flegal K. M., Dietz W. H. (2000). Establishing a standard definition for child overweight and obesity worldwide: international survey. BMJ, 320, 7244, 1240-1243.

6. Cole T. J., Flegal K. M., Nicholls D., Jackson A. A. (2007). Body mass index cut offs to define thinness in children and adolescents: international survey. BMJ, 335, 7612, 166-167.

7. Deurenberg P., Yap M., van Staveren W. A. (1998). Body mass index and percent body fat: a meta analysis among different ethnic groups. Int J Obes, 22, 12, 1164-1171.

8. Ellis K. J., Abrams A. S., Wong W. W. (1999). Monitoring childhood obesity: assessment of weight/height index. Am J Epidemiol, 150, 9, 939-946.

9. Faeh D., Braun J., Tarnutzer S., Bopp M. (2011). Obesity but not overweight is associated with increased mortality risk. Eur J Epidemiol, 26, 8, 647-655.

10. Flegal K. M., Ogden C. L. (2011). Childhood obesity: are we all speaking the same language? Adv Nutr, 2, 159S-166S.

11. Flegal K. M., Tabak C. J., Ogden C. L. (2006). Overweight in children: definitions and interpretation, Health Educ Res, 21, 6, 755-760.

12. Flegal K. M., Graubard B. I., Williamson D. F., Gail M. H. (2007). Cause-specific excess deaths associated with underweight, overweight, and obesity. JAMA, 298, 17, 2028-2037.

13. Flegal K. M., Ogden C. L., Wei R., Kuczmarski R. L., Johnson C. L. (2001). Prevalence of overweight in US children: comparison of US growth charts from the Centers for Disease Control and Prevention with other reference values for body mass index. Am J Clin Nutr, 73, 6, 1086-1093.

14. Freedman D. S., Zuguo M., Srinivasan S. R., Berenson G. S., Dietz W.H. (2007). Cardiovascular risk factors and excess adiposity among overweight children and adolescents: the Bogalusa Heart Study. J Pediatr, 150, 1, 12-17.

15. Higgins P. B., Gower B. A., Hunter G. R., Goran M. I. (2001). Defining healthrelated obesity in prepubertal children. Obes Res, 9, 4, 233-240. 
16. Ikeda J. P., Crawford P. B., Woodward-Lopez G. (2006). BMI screening in schools: helpful or harmful. Health Educ Res, 21, 6, 761-769.

17. International Obesity Task Force. (2005). EU Platform on Diet, Physical Activity and Health - Briefing Paper. Prepared in collaboration with the European Association for the Study of Obesity, Brussels (http://www.iotf.org/media/euobesity3. pdf).

18. Janssen I., Katzmarzyk P. T., Srinivasan S. R., Chen W., Malina R. M., Bouchard C., Berenson G. S. (2005). Combined influence of body mass index and waist circumference on coronary artery disease risk factors among children and adolescents. Pediatrics, 115, 6, 1623-1630.

19. Janssen I., Katzmarzyk P. T., Ross R. (2004). Waist circumference and not body mass index explains obesity-related health risk. Am J Clin Nutr, 79, 3, 379-384.

20. Knight J. A. (2011). Diseases and disorders associated with excess body weight. Ann Clin Lab Sci, 41, 2, 107-121.

21. Krebs N. F., Himes J. H., Jacobson D., Nicklas T. A., Guilday P., Styne D. (2007). Assessment of child and adolescent overweight and obesity. Pediatrics, 120, Suppl 4, S193-228.

22. Kuczmarski R. J., Ogden C. L., Grummer-Strawn L. M., Flegal K. M., Guo S. S., Wei R., Mei Z., Curtin L. R., Roche A. F., Johnson C. L. (2000). CDC growth charts: United States. Adv Data, 314, 1-27.

23. Laurson K. R., Eisenmann J. C., Welk G. J. (2011). Body Mass Index standards based on agreement with health-related body fat. Am J Prev Med, 41, 4S2, S100-S105.

24. Li C., Ford E. S., Zhao G., Mokdad A. H. (2009). Prevalence of pre-diabetes and its association with clustering of cardiometabolic risk factors and hyperinsulinemia among US adolescents: NHANES 2005-2006. Diabet Care, 32, 2, 342-347.

25. Misra A., Khurana L. (2008). Obesity and the metabolic syndrome in developing countries. J Clin Endocr Metab, 93, 11, S9-S30.

26. Monasta L., Lobstein T., Cole T. J., Vignerová J., Cattaneo A. (2011). Defining overweight and obesity in pre-school children: IOTF reference or WHO standard? Obes Rev, 12, 4, 295-300.

27. Must A., Dallal G. E., Dietz W. H. (1991). Reference data for obesity: $85^{\text {th }}$ and $95^{\text {th }}$ percentiles of body mass index (wt/ht2) and triceps skinfold thickness. Am J Clin Nutr, 53, 4, 839-846.

28. Ogden C. L., Carroll M. D., Kit B. K., Flegal K. M. (2012). Prevalence of obesity and trends in body mass index among US children and adolescents, 1999-2010. JAMA, 307, 5, 483-490.

29. Prentice A. M. (2006). The emerging epidemic of obesity in developing countries. Int J Epidemiol, 35, 1, 93-99.

30. Rasouli N., Kern P. A. (2008). Adipocytokines and the metabolic complications of obesity. J Clin Endocrinol Metab, 93, 11, Suppl 1, S64-S73. 
31. Reilly J. J. (2002). Assessment of childhood obesity: national reference data or international approach? Obes Res, 10, 8, 838-840.

32. Rodríguez G., Moreno L. A., Blay M. G., Blay V. A., Garagorri J. M., Sarría A., Bueno M. (2004). Body composition in adolescents: measurements and metabolic aspects. Int J Obes Relat Metab Disord, 28, Suppl 3, S54-58.

33. Rolland-Cachera, M. F. (2011). Childhood obesity: current definitions and recommendations for their use. Int J Pediatr Obes, 6, 5-6, 325-331.

34. Shields M., Tremblay M. S. (2010). Canadian childhood obesity estimates based on WHO, IOTF and CDC cut-points. Int J Pediatr Obes, 5, 3, 265-273.

35. Slaughter M. H., Lohman T. G., Boileau R. A., Horswill C. A., Stillman R. J., van Loan M. D., Bemben D. A. (1988). Skinfold equations for estimation of body fatness in children and youth. Hum Biol, 60, 5, 709-723.

36. Smalley K. J., Knerr N. A., Kendrick Z. V., Colliver J. A., Owen O. E. (1990). Reassessment of body mass indices. Am J Clin Nutr, 52, 3, 405-408.

37. Stettler N., Iotova V. (2010). Early growth patterns and long-term obesity risk. Curr Opin Clin Nutr Metab Care, 13, 3, 294-299.

38. Stupnicki R., Milde K., Przewęda R. (2001). Constructing growth reference curves. Papers Anthropol, 10, 268-279.

39. Stupnicki R., Tomaszewski P., Milde K., Czeczelewski J., Lichota M., Głogowska J. (2009). Body fat-based weight norms for children and youths. Ped Endocrinol Diabetol Metab, 15, 3, 139-143.

40. Wang Y., Lobstein T. (2006). Worldwide trends in childhood overweight and obesity. Int J Pediatr Obes, 1, 11-25.

\section{Address for correspondence:}

Romuald Stupnicki

Stryjenskich 10-199. 02-791 Warsaw Poland

E-mail: rstupnicki@auf.edu.pl 